\title{
ПООЩРЕНИЕ КАК ФОРМА ПОЗИТИВНОГО СТИМУЛИРОВАНИЯ В УГОЛОВНОМ ПРАВЕ
}

\begin{abstract}
Аннотация: Современный этап развития уголовного законодательства несет в себе идею либерализации и стимулирования (мотиваџии) позитивного поведения в целях применения норм поощрения. Поощрение предполагает создание определенных условий, регулирующих отношения, в рамках которых появляется потребность в позитивном поведении.
\end{abstract}

Ключевые слова: Юриспруденция, поощрение, стимул, мотиващия, позитивное право, уголовньй, поведение, обязательность, государство, волевой характер

B марте 2011 г. был принят Ф3 N 26-Ф3 “О внесении изменений в Уголовный кодекс Российской Федерации" (далее - Закон). Согласно официальной позиции Государственно-правового управления Президента он направлен на дальнейшую «либерализацию уголовного законодательства».

В современных условиях развития антропогенного общества роль личности приобретает все большую значимость. Правовое поощрение в качестве разновидности стимулирования социальной активности граждан все чаще рассматривается в юридической науке как закономерное и перспективное направление государственного управления делами общества, развивающегося на основе гуманных демократических принципов. ${ }^{2}$

В литературе термин «поощрение» рассматривается как метод мотивации, противоположный наказанию. В основе известных теоретических подходов к мотивации лежат представления, сформулированные психологической наукой, исследующей причины и механизмы целенаправленного поведения человека. С этих позиций мотивация определяется как движущая сила человеческого поведения, в основе которой находится взаимосвязь потребностей, мотивов и целей человека.

Зигмунд Фрейд считал, что на мотивацию человека можно повлиять через его подсознание; индивидуумы часто не отдают себе отчет в истинной природе желаний и силах, заставляющих их вести себя тем или иным образом.

\footnotetext{
${ }^{1}$ Федеральный закон от 07.03.2011 N 26-Ф3 «О внесении изменений в Уголовный кодекс Российской Федерации» // Российская газета. - 2011. - N 51

${ }^{2}$ Тарханов И.А. Поощрение позитивного поведения в уголовном праве. - Казань: Изд-во Казанск.ун-та, 2001. - С.5
}

В психологической литературе мотивация рассматривается как то, что побуждает деятельность человека, ради чего она совершается. ${ }^{3}$

В науке существуют разные подходы к определению понятия «мотивация». Фридерик Лютенс рассматривал «мотивацию» как «объяснение внутренних факторов или психологического состояния и отношения человека к тому, что должно быть сделано или достигнуто в качестве цели поведения». ${ }^{4}$ Он проследил этимологическую связь слова «мотивация» с лат.тоvere (что означает «побуждать») и под мотивацией понимал процесс, начинающийся с физиологической или психологической нехватки или потребности, который активизирует поведение или создает побуждение, направленное на достижение определенной цели или вознаграждения. ${ }^{5}$

А.Н.Радищев отмечает, что побуждающие средства - суть награждения разного рода. ${ }^{6}$ «Самое стимулирование, - полагает В.И.Курилов, - характеризуется диалектической связью между стимулами и личностью и предполагает такое воздействие на личность, которое формирует нужные государству и обществу потребности и иёнтересы».?

Интересную точку зрения высказал Х.Хекхаузен: «Мотивация мыслится как процесс выбора между различными возможными действиями, процесс регулиру-

\footnotetext{
${ }^{3}$ См.: Краткий психологический словарь. - М., 1985.

4 Люненс Ф. Организационное поведение / Пер. с анг. - М.: ИНФРА-М, 1999. - С. 161

${ }^{5}$ Там же.

${ }^{6}$ См.: Радищев А.Н. О законоположениях // Избранные философские сочинения. - М., 1949. - С. 405.

${ }^{7}$ См.: Курилов В.И. Личность. Труд. Право. - М.: Юрид.лит., 1989. - C. 125
} 


\section{Политика и общество 1 (97) • 2013}

ющий, направляющий действие на достижение специфических для данного мотива целевых состояний и поддерживающих эту направленность». ${ }^{8}$

Правовое стимулирование отличается тем, что воздействие на личность осуществляется посредством закрепления в правовых нормах оснований и предпосылок приобретения субъектом каких-либо социальных благ. Последние призваны и способны удовлетворить его актуальные потребности. Иными словами, возможность приобретения соответствующего блага обычно реально связывается с достижением субъектом определенного социально значимого результата. ${ }^{9}$

Поощрение как метод мотивации в уголовном праве должен рассматриваться как элемент согласования целей объекта и субъекта поощрения предполагает создание определенных условий, регулирующих отношения, в рамках которых появляется потребность в позитивном поведении для 1) освобождения от уголовной ответственности; 2) освобождения от наказания; 3) применения амнистии или помилования.

Правовые меры поощрения (т.е. закрепленные в определенных нормах права стимулы) применяются при наличии предусмотренных законом (или иным нормативным актом) оснований и приводят к конкретным, позитивным для субъекта последствиям. ${ }^{10}$

В литературе высказывается мнение, что при стимулировании социально желательного поведения посредством поощрения место санкции как негативного последствия неправомерного поведения занимает указание на определенный вид награды за достижение субъектом предусмотренных законом результатов. Нельзя не заметить, что и в том, и в другом случае законодатель. Стремится активно воздействовать на сознание и волю субъекта с тем, чтобы «Последний сделал правильный выбор (выполнение обязанностей, соблюдение запрета, поощряемое поведение). Неслучайно в юридической литературе предлагается выделить «отрицательное» (негативное) и «положительное» (позитивное) стимулирование. ${ }^{11} \mathrm{C}$ рассма-

\footnotetext{
${ }^{8}$ Хекхаузен Х. Мотивация и деятельность. - М.: Педагогика, 1986. - T.1. C. $33-35$

9 Тарханов И.А. Поощрение позитивного поведения в уголовном праве. - Казань: Изд-во Казанск.ун-та, 2001. - С.5

${ }^{10}$ Тарханов И.А. Поощрение позитивного поведения в уголовном праве. - Казань: Изд-во Казанск.ун-та, 2001. - С.20

${ }^{11}$ Грибалев Н.П., Сухин В.А. Проблемы материального и морального стимулирования труда // Право и социальное пла-
}

триваемых позиций положительное стимулирование должного правового поведения осуществляется посредством «обещания» применения поощрения, а отрицательное стимулирование - посредством угрозы применения различных мер негативной ответственности (к примеру - наказания). Причем, по мнению И.Э.Звечаровского, в основе подразделения стимулирования на положительное и отрицательное лежит не характер последствий уже содеянного лицом ${ }^{12}$, а характер самих стимулов, побуждающих такое лицо к желаемому поведению ${ }^{13}$.

Соглашаясь с подобным подходом и выводом, необходимо отметить следующее. Наказание и поощрение направлены на достижение единого конечного результата (правомерное поведение), поэтому в рамках процесса правового стимулирования они тесно связаны друг с другом. Как справедливо полагают Ю.Б.Голик и Б.Г.Прошкин, в этих рамках речь должна идти не об абсолютных недостатках другого, а об их комплексном и системном применении ${ }^{14}$. Однако рассматривать правовое поощрение в качестве положительного стимула, подкрепляющего наказание ${ }^{15}$ можно лишь с известной степенью условности: обещание исключения у головной ответственности лица при добровольном отказе (как акт уголовно-правового поощрения) имеет собственный стимулирующий заряд, является особым стимулирующим фактором. Нельзя не учитывать также, что отлична и реакция государства на факты неправомерного (преступного) и правомерного (социально желаемого) поведения субъектов. В данном случае она достигает значения противоположности и предполагает существенный стимулирующий эффект. Однако означает ли это, что к числу стимулирующих следует относить только такие нормы, которые оснащены санкциями (указанием на негативные или позитивные последствия для субъекта).

В литературе эта проблема решается неоднозначно. C позиции науки управления в аспекте правового регулирования некоторые авторы к стимулам относят

нирование. - М., 1981. - С. 136; Голик .В. Уголовно-правовое стимулирование позитивного поведения: вопросы теории. - Новосибирск: Изд-во Новосибирск. Ун-та, 1992.

${ }^{12}$ Короблев А.И, Усс А.В., Голик Ю.В. Уголовно-правовая политика. - Красноярск, 1991. - С. 216

13 Звечаровский И.Э. Указ соч. - С. 84

${ }^{14}$ Голик Ю.В., Прошкин Б.Г. Указ. Соч. - С.3.

15 Звечаровский И.Э. Указ соч. - С. 86. 
Государство и гражданское общество

все правовые средства, которые побуждают людей к заданному поведению. ${ }^{16}$

Позитивное право в юридической науке часто называют правом в объективном смысле, т.е. объективным правом. Другими словами, позитивное право - нормы поведения, которые создаются (или признаются) людьми и властно утверждаются как постоянный и непререкаемый императивный критерий для обязательного поведения. Они создаются (или признаются), чтобы императивно, в общеобязательном порядке, определять, что юридически дозволено, а что - не дозволено. Они получают определенное внешнее выражение в виде законов, юридических прецедентов и иных источников. ${ }^{17}$ Позитивное право можно признать некоторым искусственным образованием и притом - постоянно существующим, «заведенным» на непрерывное действие для решения жизненных ситуаций внешним образованием, существующим в государстве. ${ }^{18}$

Правовое поощрение представляет собой разновидность позитивного стимулирования. «Правовые нормы поощрения, - пишет В.М. Баранов, - предполагают выполнение юридических обязанностей, но предназначены они для стимулирования более социально ценных вариантов поведения». ${ }^{19}$

К важнейшим признакам (свойствам) позитивного правового стимулирования в уголовном праве можно отнести:

1) общеобязательную нормативность.

2) определенность содержания (формальную определенность).

3) волевой характер.

4) связь с государством.

Обцеобязательная нормативность поощрения как формы позитивного стимулирования в уголовном праве заключается в том, что нормы уголовного права распространяются на круг лиц и связывается с обстоятельствами различного характера. Оно применяется в

${ }^{16}$ Никитинский В.И., Глазырин В.В. Общие законы управления и правовое регулирование // Советское государство и право. - 1979. - № 9. - С. 136

${ }^{17}$ Власенко Н.А. Теория государства и права. Научно-практическое пособие. - М.: ИЗиСП. - М.: ИД Юриспруденция, 2009. - C.112.

${ }^{18}$ Алексеев С.С. Право: азбука - теория - философия. Опыт комплексного исследования. М., 1999.

19 Баранов В.М. Поощрительные нормы советского социалистического права. - Саратов: Изд-во Саратовского ун-та, 1978. - C. 7 отношении лица, в действиях которого содержатся все признаки состава преступления, иначе говоря, в отношении виновного в преступлении.

Общеобязательная нормативность - это важнейшее свойство позитивного права, собственно, оно и определяет его содержание, поскольку именно нормативное выражение в виде общеобязательных правил поведения от имени государства, и есть содержание позитивного права. ${ }^{20}$

Определенность содержания (формальная определенность) представляет собой способность права предельно точно, в письменном виде фиксировать и закреплять требования, предъявляемые к поведению виновных в преступлении; определять факты, обстоятельства и нравственные регулятивы для применения к ним мер поощрения. Существует мнение о том, что данное свойство позволяет «самым точным образом определять границы внешней свободы, а также последствия нарушения этих границ». ${ }^{21}$

Общее понятие правомерности предполагает его конкретизацию, когда речь идет о сфере уголовноправового регулирования. Известно, что одной из основных социально-правовых функций и задач уголовного законодательства является обозначение четких разграничений между преступным и не преступным поведением. В рамках формальной определенности уголовного законодательства четко регламентированы общественно-опасные (вредные) деяния, которые признаются преступлениями (ч.2 ст. 2 УК РФ).

Эта способность (свойство) позволяет точно, емко и четко определить содержание правовых норм и механизм их внешней реализации.

Волевой характер мер поощрения означает, что право принимается и реализуется по воле и в интересах соответствующих сил. Это свойство раскрывает сущность права, так как становится ясно, в чьих интересах принимается правовая норма и как она реализуется.

Связь с государством проявляется в том, что большинство правовых норм получает регламентацию через законотворческую деятельность государственных органов.

Например, в ознаменование 65-летия Победы в Великой Отечественной войне 1941 - 1945 годов, руко-

\footnotetext{
${ }^{20}$ Власенко Н.А. Теория государства и права. Научно-практическое пособие. - М.: ИЗиСП. - М.: ИД Юриспруденция, 2009. - C.113.

${ }^{21}$ Алексеев С.С. Право: азбука - теория - философия. Опыт комплексного исследования. М., 1999. - С. 245
} 


\section{Политика и общество $1(97) \cdot 2013$}

водствуясь принципом гуманизма, в соответствии с пунктом «ж» части 1 статьи 103 Конституции Российской Федерации Государственная Дума Федерального Собрания Российской Федерации постановила освободить от наказания в виде лишения свободы осужденных: 1) ветеранов Великой Отечественной войны; 2) бывших узников концлагерей, гетто, других мест принудительного содержания, созданных фашистами или их союзниками в период Второй мировой войны. ${ }^{22}$

Государство также обеспечивает, гарантирует своей властью, посредством особого правоохранительного механизма исполнение установленных им юридических норм. За правом всегда стоит государственный правоохранительный аппарат, способный реализовать принятые нормы.

Например, возложить применение Постановления Государственной Думы Федерального Собрания Российской Федерации «Об объявлении амнистии в связи с 65-летием Победы в Великой Отечественной войне 1941 - 1945 годов» (далее - применение акта об амнистии) на:

1) исправительные учреждения и следственные изоляторы - в отношении осужденных к лишению свободы, приговоры по делам которых вступили в законную силу.

ИсполнениеПостановления Государственной Думы Федерального Собрания Российской Федерации «Об объявлении амнистии в связи с 65-летием Победы в Великой Отечественной войне 1941 - 1945 годов» (далее - Постановление об амнистии) в отношении указанных осужденных производится по утвержденному прокурором постановлению начальника исправительного учреждения или начальника следственного изолятора. К направляемому прокурору для утверждения постановлению о применении к осужденному акта об амнистии прилагаются личное дело осужденного, справка о поощрениях и взысканиях, другие необходимые документы;

2) органы дознания и органы предварительного следствия - в отношении подозреваемых и обвиняемых, дела и материалы о преступлениях которых находятся в производстве этих органов;

3) суды - в отношении лиц, дела о преступлениях которых находятся в производстве этих судов и не

\footnotetext{
${ }^{22}$ Постановление ГД ФС РФ от 16.04.2010 N 3519-5 ГД «Об объявлении амнистии в связи с 65 -летием Победы в Великой Отечественной войне 1941 - 1945 годов» // Российская газета. $-2010 .-\mathrm{N} 84$
}

рассмотрены до дня вступления в силу Постановления об амнистии, а также лиц, дела о преступлениях которых рассмотрены, но приговоры судов не вступили в законную силу. ${ }^{23}$

Таким образом, поощрение как форму позитивного стимулирования в уголовном праве можно определить как закрепленную в определенных нормах права систему общеобязательных формально определенных, издаваемых или санкционируемых государством стимулов, предполагающих выполнение юридических обязанностей через возведенную в закон волю и интересы общества, являющихся властным мотивационным регулятором в рамках уголовно-правовых отношений.

\section{Библиография:}

1. Алексеев С.С. Право: азбука - теория - философия. Опыт комплексного исследования. М., 1999.

2. Баранов В.М. Поощрительные нормы советского социалистического права. - Саратов: Изд-во Саратовского ун-та, 1978. - С. 7

3. Власенко Н.А. Теория государства и права. Научно-практическое пособие. - М.: ИЗиСП. - М.: ИД Юриспруденция, 2009. - С.112.

4. Голик .В. Уголовно-правовое стимулирование позитивного поведения: вопросы теории. - Новосибирск: Изд-во Новосибирск. Ун-та, 1992.

5. Грибалев Н.П., Сухин В.А. Проблемы материального и морального стимулирования труда // Право и социальное планирование. - М., 1981. - С. 136;

6. Короблев А.И, Усс А.В., Голик Ю.В. Уголовноправовая политика. - Красноярск, 1991. - С. 216

7. Краткий психологический словарь. - М., 1985.

8. Курилов В.И. Личность. Труд. Право. - М.: Юрид. лит., 1989. - С. 125

9. Люненс Ф. Организационное поведение / Пер. с анг. - М.: ИНФРА-М, 1999. - С. 161

10. Никитинский В.И., Глазырин В.В. Общие законы управления и правовое регулирование // Советское государство и право. - 1979. - № 9. - С. 136

\footnotetext{
${ }^{23}$ Постановление ГД ФС РФ от 16.04.2010 N 3521-5 ГД «О порядке применения Постановления Государственной Думы Федерального Собрания Российской Федерации «Об объявлении амнистии в связи с 65-летием Победы в Великой Отечественной войне 1941 - 1945 годов» // Российская газета. $-2010 .-\mathrm{N} 84$
} 
Государство и гражданское общество

11. Постановление ГД ФС РФ от 16.04.2010 N 3519-5 ГД “Об объявлении амнистии в связи с 65-летием Победы в Великой Отечественной войне 1941 - 1945 годов" // Российская газета. - 2010. - N 84

12. Постановление ГД ФС РФ от 16.04.2010 N 3521-5 ГД “О порядке применения Постановления Государственной Думы Федерального Собрания Российской Федерации “Об объявлении амнистии в связи с 65-летием Победы в Великой Отечественной войне 1941 - 1945 годов" // Российская газета. $-2010 .-\mathrm{N} 84$

13. Радищев А.Н. О законоположениях // Избранные философские сочинения. - М., 1949. - С. 405.

14. Тарханов И.А. Поощрение позитивного поведения в уголовном праве. - Казань: Изд-во Казанск. ун-та, 2001. - С.5

15. Федеральный закон от 07.03.2011 N 26-Ф3 “О внесении изменений в Уголовный кодекс Российской Федерации" // Российская газета. - 2011. - N 51

16. Хекхаузен Х. Мотивация и деятельность. - М.: Педагогика, 1986. - Т.1. С. 33-35

\section{References (transliteration):}

1. Alekseev S.S. Pravo: azbuka - teoriya - filosofiya. Opyt kompleksnogo issledovaniya. M., 1999.
2. Baranov V.M. Pooshchritel'nye normy sovetskogo sotsialisticheskogo prava. - Saratov: Izd-vo Saratovskogo un-ta, 1978. - S. 7

3. Vlasenko N.A. Teoriya gosudarstva i prava. Nauchno-prakticheskoe posobie. - M.: IZiSP. - M.: ID Yurisprudentsiya, 2009. - S.112.

4. Golik .V. Ugolovno-pravovoe stimulirovanie pozitivnogo povedeniya: voprosy teorii. - Novosibirsk: Izd-vo Novosibirsk. Un-ta, 1992.

5. Gribalev N.P., Sukhin V.A. Problemy material'nogo i moral'nogo stimulirovaniya truda // Pravo i sotsial'noe planirovanie. - M., 1981. - S. 136;

6. Koroblev A.I, Uss A.V., Golik Yu.V. Ugolovno-pravovaya politika. - Krasnoyarsk, 1991. - S. 216

7. Kurilov V.I. Lichnost'. Trud. Pravo. - M.: Yurid.lit., 1989. - S. 125

8. Lyunens F. Organizatsionnoe povedenie / Per. s ang. - M.: INFRA-M, 1999. - S. 161

9. Nikitinskiy V.I., Glazyrin V.V. Obshchie zakony upravleniya i pravovoe regulirovanie // Sovetskoe gosudarstvo i pravo. - 1979. - № 9. - S. 136

10. Radishchev A.N. O zakonopolozheniyakh // Izbrannye filosofskie sochineniya. - M., 1949. - S. 405.

11. Tarkhanov I.A. Pooshchrenie pozitivnogo povedeniya v ugolovnom prave. - Kazan': Izd-vo Kazansk.unta, 2001. - S.5

12. Khekkhauzen Kh. Motivatsiya i deyatel'nost'. - M.: Pedagogika, 1986. - T.1. S. 33-35 